\title{
The Relationship between Emotional Intelligence and Creative Thinking with Academic Achievement of Primary School Students of Fifth Grade
}

\author{
Mehdi Zirak \\ Department of Education, Torbat-e Heydarieh Branch, Islamic Azad University, Torbat-e Heydarieh, Iran \\ E-mail: Mehdizirak45@gmail.com \\ Elahe Ahmadian \\ Department of Education, Torbat-e Heydarieh Branch, Islamic Azad University, Torbat-e Heydarieh, Iran
}

\section{Doi:10.5901/mjss.2015.v6n1p598}

\begin{abstract}
This study was conducted to explore the relationship between emotional intelligence and creative thinking with academic achievement. This descriptive - correlation study was performed on 156 male and female students of Torbat-e-Heydarieh who were selected by census method during 2012-2013. Data was collected using Bradberry - Greaves' questionnaire of emotional intelligence and Abedi's questionnaire of creative thinking. The mean scores of students were used as an index of academic achievement. Data were analyzed by descriptive statistics, independent $t$-test, Pearson correlation coefficient and multiple regressions using Spss20 software. There is no significant relationship between emotional intelligence and academic achievement, but the relationship between creative thinking and academic achievement was positive and significant. Among the components of emotional intelligence and creative thinking, the relationship between social awareness and fluency with academic achievement was significant. There was no significant difference between emotional intelligence and creative thinking scores of male and female students.
\end{abstract}

Keywords: emotional intelligence, creative thinking, academic achievement

\section{Introduction}

Education is a fundamental basis of economic, social, cultural and political development of the country and nowadays. Its role in improving the living conditions of individuals and communities is clear for everyone. The society that is in transition from traditional to modern society needs qualified personnel. One of the essential tasks of education in every country is the transmission of the cultural heritage of community, to develop the talents of students and to prepare them for active participation in the community. Therefore educating people for various purposes seems necessary and success and failure in education has been a primary concern of any educational system in all communities. Students' education in all levels is in order to change the behavior, thoughts, attitudes and skills and is ultimately measured by the achievement and academic performance. Academic success and improvements of students in every community represents the success of the educational system in targeting and paying attention to satisfying individual needs. Therefore, education system is successful when students" educational improvement in various levels has the greatest and highest number. For students, grades represent their academic ability to enter the world of work and employment and higher educational levels.On the other hand, we're at the beginning of a new century and it does not seem that intelligence and success are achieved as in the past.

New theories of intelligence and creativity have been introduced and are gradually replacing the previous theories. Students not only because of the ability for reasoning, but are at the center of concerns due to creativity, emotions and interpersonal skills. Goleman(1995) argues that IQ alone is not a sign of success; emotional intelligence, social intelligence and luck also play an important role in one's success. Moreover, Robinson (2006) believes that creativity and creative thinking are as important as education and should be considered equally and with the same quality [14]. Application of creative thinking is not limited to areas such as science and art. Creative thinking is beneficial in every aspect of life. People think that creativity is manifested mainly in arts bed, while it is manifested in all areas. Creativity remains as an interesting mystery either in science, literature, music, painting, or any other area of life. Despite this fact, psychologists' attention to this fact grows every day. Hence the basis of creativity may include all of the lesson, all aspects of life, all fields of education, and even various ages although its effects on students, college students and younger ages 
is more important [33]. Hence, the aim of this study is to determine the relationship between emotional intelligence and creative thinking with academic achievement of students in the fifth grade.

\subsection{The Theoretical Framework}

\subsubsection{Emotional Intelligence}

Salavy believes that emotional intelligence is a kind of emotional processing that include paying attention to emotions, proper evaluation of them in oneself and others, systemic organization of them and appropriate instruments, in a way that improves life [9].

According to Goleman, people's success depends on their emotional intelligence and this ability is learnable and could be reformed [28]. Bradberry et al (2009) defines emotional intelligence as the ability, talent and skills to identify assess and manage the emotions of the person in dealing with people and groups [3].

Emotional intelligence theories can be divided into two groups or models. The first group is the ability based model in which the emotional intelligence is considered as a form of mental abilities therefore it is a part of cognitive intelligence. Another group is the mixed model that theorists, combine mental abilities with personality characteristics such as optimism and wellbeing. Salavy and Mayer are fans of ability based model. Bar-on considers this issue from mixed model perspective [35].

Components of emotional intelligence, according to Bradberry and Greaves are:

A. self-awareness: self-awareness includes recognition of the feeling at the moment of happening which comprises the most important part of emotional intelligence.

B. Self-management: self-management is the ability to use "awareness of Emotions" in order to remain flexible and conduct positive behaviors, is to be able to control emotional reactions in front of people and under different conditions.

C. Social Awareness: Social Awareness is the art of communicating with people and the skills to control and manage the feelings of others. This often means that you understand the thoughts and feelings of others.

D. Relationship Management: The ability to use "awareness of others' emotions" in order to succeed in controlling and managing interactions [23]

\subsubsection{Creative Thinking}

Fasiony (2006) considers creative thinking as a kind of thinking that leads to new ideas, new approaches, new perspectives and new ways to understand the objects and situations. Hennessy and Amabil (2010) believe that creativity is a concept of individual differences that attempt to explain why some people have higher potential compared to others to present new solutions to problems. Creativity will lead us to change our ways of thinking about issues and is like a driving force behind bidding the culture. In another definition it is stated that creative thinking is a thought that is characterized by its ability to discard unnecessary assumptions and calving original ideas [2].

The importance of creative thinking in the primary school revealed by knowing that acquiring correct learning habits are formed in childhood and early years of education and are enhanced during human life [47]

Creative thinking process: identification of possible solutions is the first step in the development of creative thinking. After that, it is emphasized on the extraction of hypotheses, tests and evaluations. The final step is defined by Torrance as identification of scientific discovery and communication [6]

Creative thinking components include: A- Fluency; means the ability to produce many thoughts at a determined time B-elaboration; means the ability to pay attention to the details' of a thought C-Originality; means the ability to produce new thoughts D-Flexibility: means the ability to change the thoughts and make diversity in making thoughts [36].

\subsubsection{Academic Achievement}

Khoynezhad defines academic achievement as the students' achievement to educational goals which is usually in cognitive domains and in a specific study subject. Shelviry considers progression as the learned amount in the institutes measured by various tests such as math, science, etc. [13]. Merriam Webster believes that educational development include the quality and quantity of student work [42]. Progress in various fields of life such as sports, education, industry, occupation, etc. is both important for children and the people around them. In the formal education sector, academic achievement is the main scale to measure the training to gain the curriculum goals [1]. 
Studying the factors affecting student academic achievement is a complex issue, because it is a multi-dimensional element and is specifically related to intelligence, motivation, personality characteristics, locus of control, emotional atmosphere in the family, social and economic status of the family, teaching methods, classroom emotional atmosphere and the feeling of success in courses tests. These factors and variables are so intertwined and have interactions that determining the role and contribution of each is difficult [21]. These factors may decrease academic improvement, such as anxiety or to increase it, such as mental ability and emotional and social maturity [38].

\section{Research Background}

Researches in these areas are widespread. Samari et al (2007) found that emotional intelligence has a positive correlation with academic success of students.

Investigating the emotional intelligence and its relationship with academic achievement in urban and rural girls in Qeshm city having 11 years age range showed that emotional intelligence is positively related to educational attainment [40].

Habiballah(2009) did not find a significant relationship between creativity and academic achievement of boys and girls. Zahabioun and Ahmadi (2009) found that there is no significant relationship between the rate of creative thinking and variables such as sex and parents' education level. Hassanzadeh and Imanifar (2010) investigated the relationship between creativity and self-esteem and concluded that there is no significant relationship between creativity and academic achievement.

Pearson correlation analysis showed that different aspects of creativity both for boys and for girls are associated with academic achievement [26]. In another study results obtained shows that boys, in all aspects of verbal creativity expect originality scale, are not different from girls [37]. The result of the study by Nofersty and Moein o Ighorabayi, (2010) confirms the significant positive relationship between emotional intelligence and creativity. Many experts emphasize that the relationship between emotional intelligence variables and academic achievements in different age groups and both sexes have a close relationship [7]. Niaz and Saud (2008) showed that there was a significant positive relationship between creativity and academic achievement.James Kristid worked on 235 freshmen to study the correlation between emotional intelligence and academic achievement. The results showed that there is a small correlation between emotional intelligence and academic achievement. Jiun Song et al (2009) showed that in Shanghai university students, after controlling the mental abilities, it is the emotional intelligence that effect on academic performance. Another study that was conducted on academic achievement in America showed that while the family has a great impact on students' achievement, itcannot demonstrate the gap between academic achievements in America compared with other developed countries [41]. According to extensive studies concerning the behavior of an individual based on emotional intelligence it was determined that emotional intelligence has a significant effect on academic achievement [44]. Baharat(2011) in an experiment found that there is a significant difference between the mean emotional intelligence score in rural and urban adolescents. He also adds that gender has no significant effect on emotional intelligence.

Studies conducted by Ziogoziya in 2010 revealed that for females and for males, creativity is related to academic achievement [6].

Dahl (2012) in an experiment that was conducted on junior high school children showed that by elimination of the effect of intelligence, there is no significant relationship between creativity and academic achievement.

Roneko research results (2007) showed that creativity is positively significantly related with academic achievement. Researchers such as Estrecher et al (1996), Peterson et al (2008) and Naderi et al (2010) found that academic achievement can be predicted through creativity scores [25].

The results of Chan (2005) showed that a significant positive relationship exists between perceived creativity by children and their emotional intelligence [29]

Nelson et al (2004) studies showed that there is a significant relationship between emotional intelligence and creative thinking skills which is an important factor in academic achievement [15].

\section{Hypotheses}

Hypothesis 1: There is a significant relationship between emotional intelligence with academic achievement of students.

Hypothesis 2: There is a significant relationship between creative thinking with academic achievement of students

Hypothesis 3: There is a significant difference between female and male students in terms of emotional 
intelligence.

Hypothesis 4: There is a significant difference between female and male students in terms of creative thinking.

\section{Methodology}

The present research has a descriptive design or more precisely is correlational predictive type design

\subsection{Population, sample size and sampling method}

The population included all the fifth grade students in the academic year 2012-2013 in public schools of Torbat e Heydatiyeh city .In the present study, due to the limitation of the population, and on the basis of consultation with teachers and counselors, selected sample size include elementary male and female students of Torbat e Heydariyeh selected by census method sampling.

\subsection{Data collection}

Various sources such as books, academic journals and dissertations were used in the theoretical framework. Data gathering was performed using standard questionnaire and distributing them among samples to gather the required data.

\subsection{Research tools}

\subsubsection{Emotional Intelligence Questionnaire}

The questionnaire was designed by Bradberry and Greaves in 2005 and consists of 28 items which measure components of self-awareness, self-management, social awareness and relationship management. Scoring was prepared based on the likert scale questions starting from "never" to "always" [15].

The maximum score on this exam is 100 . Reliability coefficients obtained between two consecutive runs for the four skills of emotional intelligence included 0.73 for self-awareness, 0.87 for self-management, 0.78 for social awareness and 0.76 for relationship management that are significant at 0.99 level. Investigation of the data in the second group using chronbach method showed that all the questions have a significant positive correlation with the whole test and omitting any of the questions does not result in the significant increase of the whole test reliability [16].

\subsubsection{Creative thinking questionnaire}

The questionnaire was developed by Dr. Abedi in 1993 and it consists of 60 questions which have three options that measure the four elements of creativity including fluidity, creativity, flexibility and expansion [33].

\section{Research Findings}

\subsection{Descriptive findings}

Table 1: Distribution of the sample frequency in terms of "gender"

\begin{tabular}{|c|c|c|c|}
\hline Characteristic & Subcategory & Frequency & Frequency Percentage \\
\hline \multirow{2}{*}{ Gender } & Male & 80 & $3 / 51 \%$ \\
\cline { 2 - 4 } & Female & 76 & $7 / 48 \%$ \\
\hline
\end{tabular}

\subsection{Hypotheses testing}

\subsubsection{Testing the first hypothesis}

First research hypothesis is as follows:

There is a significant relationship between the emotional intelligence and academic achievement of students: 
Table 2: Correlation coefficient results between emotional intelligence and academic achievement

\begin{tabular}{|l|c|c|c|c|c|c|}
\hline & 1 & 2 & 3 & 4 & 5 & 6 \\
\hline 1- Self Awareness & 1 & & & & & \\
\hline 2-Self Management & 0.50 & 1 & & & & \\
\hline 3- Social Awareness & 0.34 & 0.49 & 1 & & & \\
\hline 4- Relationship Management & 0.43 & 0.43 & 0.43 & 1 & & \\
\hline 5-Academic Achievement & 0.07 & 0.07 & 0.26 & -0.004 & 1 & \\
\hline 6- Total Emotional Intelligence & 0.73 & 0.822 & 0.77 & 0.77 & 0.11 & 1 \\
\hline
\end{tabular}

Results of the correlation coefficient shows that there is no significant relationship betweenself-awareness and academic achievement ( $r=0.07, p>0.05)$, self-management and academic achievement $(r=0.07, p>0.05)$, relationship management and academic achievement $(r=-0.004, p>0.05)$ as well as total emotional intelligence and academic achievement $(r=0.11$, $p>0.05)$. Therefore, the hypothesis is rejected, and it is said that there is no significant relationship between total emotional intelligence and academic achievement. Moreover, results of the correlation coefficient shows that there is a direct significant relationship between the components of social awareness and academic achievement $(r=0.26, p<0.01)$,. This means that the more increase in social awareness the more increase in the academic achievements of the students and vice versa. The stepwise regression was used to test the relationship between emotional intelligence and academic achievement. The stepwise regression is a method in which the predictive variables entered the analysis stepwise and the effects of predictive variables is investigated on the criterion variable.

Table 3: Correlation coefficient between the criterion variable of academic achievement and predictive variable of emotional intelligence

\begin{tabular}{|c|c|c|c|c|}
\hline Step & $\begin{array}{c}\text { Correlation } \\
\text { coefficient }\end{array}$ & $\begin{array}{c}\text { Squared } \\
\text { correlation coefficient }\end{array}$ & $\begin{array}{c}\text { Modified squared } \\
\text { correlation coefficient }\end{array}$ & $\begin{array}{c}\text { Estimated } \\
\text { standard error }\end{array}$ \\
\hline First & 0.26 & 0.06 & 0.06 & 1.59 \\
\hline
\end{tabular}

Social awareness variable entered the equation. Multiple correlation coefficientswere calculated 0.26 and the coefficient of determination was 0.06 . In other words 0.06 percent of the variance academic achievement can be explained by the predictor variables.

Table 4: Results of regression analysis, the criterion variable of academic achievement and predictive variable of emotional intelligence

\begin{tabular}{|c|c|c|c|c|c|c|}
\hline Step & Model & Total squares & Degree of freedom & Total squares & $\mathrm{F}$ & Significance level \\
\hline \multirow{3}{*}{1} & Regression & 28.86 & 1 & 28.86 & \multirow{3}{*}{11.30} & \multirow{2}{*}{0.001} \\
\cline { 2 - 5 } & Residual & 393.24 & 154 & 2.55 & \\
\cline { 2 - 5 } & Total & 422.10 & 155 & & \\
\hline
\end{tabular}

$F_{1,154}$ with a value of 11.30 is significant at 0.001 error level. So social awareness variable has no significant role in explaining educational achievement variable

Table 5: The regression coefficient between the criterion variable of academic achievement and predictive variable of emotional intelligence

\begin{tabular}{|c|c|c|c|c|c|c|}
\hline \multicolumn{2}{|c|}{ Step } & B coefficient & Standard error & beta & $t$ & Significance level \\
\hline \multirow{2}{*}{1} & Constant coefficient & 16.27 & 0.60 & & 26.74 & 0.0001 \\
\cline { 2 - 7 } & Social awareness & 0.09 & 0.02 & 0.26 & 3.36 & 0.001 \\
\hline
\end{tabular}

Table 6: Variables that were removed from the equation

\begin{tabular}{|l|c|c|c|c|}
\hline Variable & Beta in & $\mathrm{t}$ & Significance level & correlation \\
\hline Self-awareness & -0.02 & -0.26 & 0.79 & -0.02 \\
\hline Self-management & -0.07 & -0.81 & 0.41 & -0.06 \\
\hline Relationship management & -0.14 & -1.66 & 0.09 & -0.13 \\
\hline
\end{tabular}




\subsubsection{Testing the second hypothesis}

There is a significant relationship between creative thinking and academic achievement of students.

Table 7: Correlation coefficient between creative thinking and academic achievement

\begin{tabular}{|l|c|c|c|c|c|c|}
\hline & 1 & 2 & 3 & 4 & 5 & 6 \\
\hline 1- Academic Achievement & 1 & & & & & \\
\hline 2- Fluidity & 0.34 & 1 & & & & \\
\hline 3- Creativity & 0.08 & 0.53 & 1 & & & \\
\hline 4- Flexibility & 0.09 & 0.49 & 0.54 & 1 & & \\
\hline 5-Expansion & 0.15 & 0.52 & 0.66 & 0.49 & 1 & \\
\hline 6- Creative Thinking & 0.21 & 0.83 & 0.85 & 0.74 & 0.80 & 1 \\
\hline
\end{tabular}

The results of the correlation coefficient shows that there is no significant relationship between creativity and academic achievement $(r=0.08, p>0.05)$, the expansion and academic achievement $(r=0.15, p>0.05)$ as well as the flexibility and academic achievement ( $r=0.09, \mathrm{p}>0.05)$. Moreover,

Results of the correlation coefficient shows that there is a direct significant relationship between the component of fluidity and academic achievement $(r=0.21, p<0.01)$ as well as the total score of creative thinking and academic achievement $(r=0.34, p<0.01)$. This means that the more increase in creative thinking results in the more increase of academic achievement in students and vice versa.

Moreover,the results of the correlation coefficient shows that there is a direct significant relationship between components of fluidity and academic achievement $(r=0.34, p<0.01)$.. This means that the more increase in fluidity results in better academic achievement of students and vice versa.

The stepwise regression was used to test the relationship between creative thinking and academic achievement. Stepwise regression is a method in which predictive variables enter the analysis stepwise and the effects of predictive variables was evaluated on criterion variable.

Table 8: Correlation coefficient between the criterion variable of academic achievement and predictive variable of creative thinking

\begin{tabular}{|c|c|c|c|c|}
\hline Step & $\begin{array}{c}\text { Correlation } \\
\text { coefficient }\end{array}$ & $\begin{array}{c}\text { Squared } \\
\text { correlation coefficient }\end{array}$ & $\begin{array}{c}\text { Modified squared } \\
\text { correlation coefficient }\end{array}$ & $\begin{array}{c}\text { Estimated } \\
\text { standard error }\end{array}$ \\
\hline First & 0.34 & 0.12 & 0.11 & 1.55 \\
\hline
\end{tabular}

Fluidity variable was entered into the equation. Multiple correlation coefficientswere 0.34 and the coefficient of determination obtained was 0.11 . In other words, $\% 11$ of the variance in the academic achievement can be explained by the predictive variable.

Table 9: Results of regression analysis of the criterion variable of academic achievement and predictive variable of creative thinking

\begin{tabular}{|c|c|c|c|c|c|c|}
\hline Step & Model & Total squares & Degree of freedom & Mean squares & F & Significance level \\
\hline \multirow{3}{*}{ First } & Regression & 51.43 & 1 & 51.43 & \multirow{3}{*}{21.37} & \multirow{2}{*}{0.0001} \\
\cline { 2 - 5 } & The remaining & 370.67 & 154 & 2.40 & \\
\cline { 2 - 5 } & Total & 422.10 & 155 & & \\
\hline
\end{tabular}

$F_{1,154}$ is significant at 0.0001 erorr level. So fluidity variable has a meaningful role in explaining educational achievement variable

Table 10: Regression coefficients of academic achievement criterion variable and emotional intelligence predictor

\begin{tabular}{|c|c|c|c|c|c|c|}
\hline \multicolumn{2}{|c|}{ Step } & Coefficient b & Standard error & beta & $t$ & Significance level \\
\hline \multirow{2}{*}{1} & Constant coefficient & 13.60 & 1.01 & & 13.35 & 0.0001 \\
\cline { 2 - 7 } & fluidity & 0.09 & 0.02 & 0.34 & 4.62 & 0.0001 \\
\hline
\end{tabular}


The above table shows that fluidity variable is able to predict academic achievement (Beta=0.34, $p=0.0001<0.01$.)

Table 11: variables that were excluded from the equation

\begin{tabular}{|c|c|c|c|c|c|}
\hline & Variable & Beta in & $\mathrm{t}$ & Significance level & Partial correlation \\
\hline \multirow{3}{*}{ Step 1 } & Novelty & -0.14 & -1.65 & 0.10 & -0.13 \\
\cline { 2 - 6 } & Flexibility & -0.11 & -1.28 & 0.20 & -0.10 \\
\cline { 2 - 6 } & Expansion & -0.09 & -1.07 & 0.28 & -0.08 \\
\hline
\end{tabular}

\subsubsection{Testing the third hypothesis}

The third hypothesis is as follows:

There is a significant difference between female and male students in terms of emotional intelligence

Table 12: Multiple variance analysis (MANOVA) results on male and female students regarding the emotional intelligence

\begin{tabular}{|l|c|c|c|c|c|}
\hline Test name & value & DF hypothesis & DF error & $F$ & Significance level $(p)$ \\
\hline Pilaee effect test & 0.04 & 1.71 & 4.00 & 151.000 & 0.14 \\
\hline Lamb day vilkz test & 0.95 & 1.71 & 4.00 & 151.000 & 0.14 \\
\hline Hetling effect test & 0.04 & 1.71 & 4.00 & 151.000 & 0.14 \\
\hline Test on the largest root & 0.04 & 1.71 & 4.00 & 151.000 & 0.14 \\
\hline
\end{tabular}

As it is shown on table 12,the significance level of all tests indicate that there is no significant difference between male and female regarding any of the dependent variables such as self-awareness, self-management, social awareness and relationship management. To notice the difference, results obtained from single variance analysis in MANOVA are shown in table 13.

Table 13: Results of single variance analysis in MANOVA on female and male students

\begin{tabular}{|l|c|c|c|c|c|}
\hline Variables & Total square & Degree of freedom & Mean square & F & Significance level \\
\hline Self-awareness & 96.84 & 1 & 96.84 & 3.42 & 0.06 \\
\hline Self-management & 32.92 & 1 & 32.92 & 0.63 & 0.42 \\
\hline Social awareness & 5.97 & 1 & 5.97 & 0.28 & 0.59 \\
\hline Relationship management & 106.19 & 1 & 106.19 & 2.53 & 0.11 \\
\hline
\end{tabular}

As can be observed in table 13, there is no significant difference between female and male students in terms of selfawareness, self-management, social awareness and relationship management. $(p=0.42, F=0.06, p=0.06, F=3.42, p=0.59$, $F=0.28, p=0.11, F=2.53)$.

\subsubsection{Testing the fourth hypothesis}

The fourth research hypothesis is as follows

There is a significant difference between female and male students regarding the creative thinking.

Table 14: Results of multiple variances (MANOVA) on female and male students regarding the creative thinking

\begin{tabular}{|l|c|c|c|c|c|}
\hline Test name & value & DF hypothesis & DF error & $F$ & Significance level $(p)$ \\
\hline Pilaee effect test & 0.03 & 1.53 & 4.00 & 151.00 & 0.19 \\
\hline Lamb day vilkz test & 0.96 & 1.53 & 4.00 & 151.00 & 0.19 \\
\hline Halting effect test & 0.04 & 1.53 & 4.00 & 151.00 & 0.19 \\
\hline Test on largest root & 0.04 & 1.53 & 4.00 & 151.00 & 0.19 \\
\hline
\end{tabular}

As shown in table 14 the significance level of all tests indicate that there is no significance between male and female students regarding at least one of the dependent variables such as fluidity, flexibility and expansion. 
Table 15: Results of variance analysis in MANOVA on female and male students regarding the creative thinking

\begin{tabular}{|c|c|c|c|c|c|}
\hline Variables & Total square & Degree of freedom & Mean square & $\mathrm{F}$ & Significance level \\
\hline Fluidity & 77.10 & 1 & 77.10 & 2.18 & 0.14 \\
\hline Novelty & 19.16 & 1 & 19.16 & 0.75 & 0.38 \\
\hline Flexibility & 0.005 & 1 & 0.005 & 0.0001 & 0.98 \\
\hline Expansion & 0.03 & 1 & 0.03 & 0.002 & 0.96 \\
\hline
\end{tabular}

As can be observed in table 15, there is no significant difference between female and male students regarding fluidity, novelty, flexibility and expansion

$(F=0.002, p=0.96, F=0.0001, p=0.98, F=0.75, p=0.38, F=2.18, p=0.14)$.

Table 16: Results of t test to compare the mean of academic achievement in female and male groups

\begin{tabular}{|c|c|c|c|c|c|}
\hline \multirow{2}{*}{ Variable } & \multicolumn{2}{|c|}{ Male } & \multicolumn{2}{c|}{ Female } & \multirow{2}{*}{ Independent test } \\
\cline { 2 - 5 } & mean & SD & mean & SD & \\
\hline Academic achievement & 18.79 & 1.21 & 17.78 & 1.85 & 0.0001 \\
\hline
\end{tabular}

Table 17: Results of t test to compare mean emotional intelligence component in female and male groups

\begin{tabular}{|l|c|c|c|c|c|}
\hline \multirow{2}{*}{ Variable } & \multicolumn{2}{|c|}{ Female } & \multicolumn{2}{c|}{ Male } & \multirow{2}{*}{ Independent t test } \\
\cline { 2 - 5 } & Mean & SD & Mean & SD & \\
\hline Self-awareness & 23.22 & 5.92 & 24.80 & 4.68 & 0.06 \\
\hline Self-management & 36.86 & 8.13 & 37.78 & 6.23 & 0.43 \\
\hline Social awareness & 21.32 & 5.44 & 20.93 & 3.54 & 0.59 \\
\hline Relationship management & 32.73 & 7.14 & 34.38 & 5.75 & 0.11 \\
\hline
\end{tabular}

Table 18: Result of $t$ test to compare componants of creative thinking in females and males

\begin{tabular}{|c|c|c|c|c|c|}
\hline \multirow{2}{*}{ Variable } & \multicolumn{2}{|c|}{ Female } & \multicolumn{2}{c|}{ Male } & \multirow{2}{*}{ Independent test } \\
\cline { 2 - 5 } & mean & SD & mean & SD & 0.14 \\
\hline Fluidity & 49.13 & 6.21 & 47.72 & 5.67 & 0.38 \\
\hline Novelty & 33.97 & 5.15 & 34.67 & 4.95 & 0.98 \\
\hline Flexibility & 24.26 & 3.24 & 24.27 & 3.73 & 0.96 \\
\hline Expansion & 22.95 & 3.72 & 22.92 & 3.86 & \\
\hline
\end{tabular}

Table 19: $t$ test result to compare the mean of total emotional intelligence and creative thinking in male and female group

\begin{tabular}{|c|c|c|c|c|c|}
\hline \multirow{2}{*}{ Variable } & \multicolumn{2}{|c|}{ Female } & \multicolumn{2}{c|}{ Male } & \multirow{2}{*}{ Independent $\mathrm{t}$ test } \\
\cline { 2 - 5 } & Mean & SD & Mean & SD & \\
\hline Emotional intelligence & 114.15 & 20.14 & 117.91 & 15.93 & 0.20 \\
\hline Creative thinking & 130.32 & 15.06 & 129.60 & 14.83 & 0.76 \\
\hline
\end{tabular}

Results of the above tables show the mean and standard deviation of research variables among female and male students. Independent $t$ test showed that female and male students were different only in terms of academic achievement.

\section{Discussion}

First research hypothesis: "There is a significant relationship between emotional intelligence and academic achievement of students".

The results of the correlation coefficient showed no significant relationship between self-awareness and academic achievement $(r=0.07, p>0.05)$, self-management and academic achievement $(r=0.07, p>0.05)$, relationship management and academic achievement $(r=-0.004, p>0.05)$ and total score of emotional intelligence $(r=0.11, p>0.05)$ but there is a direct correlation between the components of social awareness and academic achievement $(r=0.26, p<0.01)$.. This means that the more the social awareness increases the better the academic achievement becomes and vice versa. This 
is because (Beta=0.26, $\mathrm{p}=0.06$ ) and the social awareness is able to predict the academic achievement. Regression analysis showed 06.0 percent of the variance in academic achievement is predictive by self-awareness. Investigation on emotional intelligence and its relationship to academic achievement in urban and rural girls. Of Qeshm city with an age range of 11 years showed that emotional intelligence is positively related to academic achievement [40]. Many experts assert that there is a close relationship between emotional intelligence variable and academic achievement of males and females of different age range [7].

Jiun Song et al (2009) showed that in Shanghai university students emotional intelligence, after controlling the mental abilities, is effective on academic performance.

Zare (2001), in his study using Bar on questionnaire, investigated the ability to predict the emotional intelligence in academic success of third grade high school students. The results showed a significant relationship $(68.0=r)$ between emotional intelligence and academic success.

In Mansouri's (2001) study, a correlation was found between emotional intelligence test score and academic achievement. Dehshiri (2003) also found that the correlation between emotional intelligence and academic achievement was $(r=37.0)$ that is statsically significant at $p 01.0$ level.

Yousefi and Mokhir (2003) investigated the relationship between visual reasoning and emotional awareness with academic achievement. Analysis of the findings showed that there is a significant relationship between two components of emotional awareness and academic achievement of all the students.

Kanagousi and Piterson (1998) studying 175 high school students using Bar on emotional intelligence questionnaire found that students with higher emotional intelligence face less failure at school, home and relationship with friends and at working place compared to other students[21].

Parker et al (2004) studying 667 high school students in Canada found that the correlation between emotional intelligence and academic achievement was 41.0 and emotional intelligence was significantly predictive of academic achievement. A large body of studies regarding the individuals' behavior according to emotional intelligence revealed that the emotional intelligence had a significant effect on the academic achievement [44].

Estonlimo (2002) investigates the relationship between emotional intelligence and academic achievement of students using the statistical test of pearson correlation coefficient showed that there is a great correlation between academic achievement and emotional intelligence [7].

Results of laliFaz and Askari (2008) study investigating the relationship between emotional intelligence, its levels and academic achievement showed that there was no significant relationship between emotional intelligence and interpersonal, intrapersonal, dealing with stress and general mood with academic achievement and the only significant relationship was about the coping area.

Sobhani (2004) studied the university students and stated that there was no significant relationship between emotional intelligence and academic achievement.

Tamanaee Far et al (2010) investigated the relationship between emotional intelligence and academic achievement and found no significant relationship between them. Keshavarzi Arshadi (2009) found that there is no significant relationship between emotional intelligence and academic achievement.

Results of Sharifi et al (2011) showed that there was no significant relationship between creativity and emotional intelligence with academic achievement.

Vatuzesky and Alsma (2004) studing 39 gifted teenagers using regression analysis found that emotional intelligence does not have a significant relationship with academic and social achievements.

Admula et al (2010) found that there was no significant relationship between academic achievement and creativity with emotional intelligence. A general investigation shows that the results of the present study is consistant with the studies by Sobhani (2004), Lalifaz and Askari (2008),KeshavarziArshadi (2009),Tamanaee Far et al(2010), Sharifi et al (2011),Vatuzeski and Alsma (2004),Admola et al (2010). Yet it's not consistant with the results of studies by Kanagosi and Peterson (1998), Bar on (1999), Estonlimo (2002), Elias et al (2003),Parker et al (2004) Der elgo (2004), Vernon et al (2008) Jin song et al (2009), Zare (2001), Mansouri (2001), Dehshiri (1382), FarMahiniFarahani (2008), Sorudi and Rahimi (2010).

It seems that the reason of this discrepancies' is due to the wide domain of emotional intelligence. On the other hand, most studies are carried out on above the elementary school students which according to Sharifi et al (2011)the older the person becomes the more role the creativity and emotional intelligence plays on one's academic achievement. Their study showed that in last years of high school only cognitive intelligence has a significant role in academic achievement while in bachelors level in addition to cognitive intelligence, the creativity is leading and in masters and PhD both creativity and emotional intelligence are leading in academic achievement.In addition,according to other results,emotional intelligence is not able to predict the academic achievement.Maybe as the findings of this study and 
some other studies show,this structure could be the basis of predicting the academic achievements.Another reason for the discrepancy of the results might be due to the reasechers lack of attention to various theories of emotional intelligence. Accordingto Mayer and Salvy view emotional intelligence is a skill and is somehow related to information processing. Yet on the other hand Bar on believes that it is a personality feature.Therefore,based on the type of emotional intelligence view used for investigation it could show different relationships with academic performance which this fact requires additional studies.

Second research hypothesis: There is a significant relationship between creative thinking and academic achievement. "

The results of correlation coefficient shows that there is no significant relationship between the creativity and academic achievement $(r=0.08, p>0.05)$ expansion and academic achievement $(r=0.15, p>0.05)$ flexibility and academic achievement $(r=0.09, p>0.05)$. However, there is a significant relationship between components of fluidity and academic achievement $(r=0.34, p<0.01)$. This means that the more the fluidity increases the more increase in academic achievement occurs and vice versa. Because (Beta $=0.34, p=0.0001<0.01$ ), so fluidity variable is able to predict the academic achievement. In stepwise regression analysis, the multiple correlation coefficientswere 34.0 and coefficient of determination was 11.0 respectively. In other words, $11 \%$ of the academic achievement variance is explained by the components of fluidity. Furthermore, creative thinking $(r=0.21, p<0.01)$ is associated with academic achievement with 99\% reliability.Ziogoziya(2010), showed that creativity is associated with the academic achievement of females and males [6]. Research results of Ronko (2007) and Asha (1980) show that creativity is positively and significantly associated with academic achievement. Researchers such as sterocher et al (1996), Peterson et al (2008), Naderi et al. (2010) found that academic achievement can be predicted through creativity scores [25]. According to Eye study (1999), creativity is highly correlated with academic achievement. Studies by Nelson and Cox (2004), showed a significant correlation between emotional intelligence and creative thinking skills which is an important factor in academic achievement [15].

Jababin and Ahmed khan (2013), found in a research that a significant positive relationship exists between creativity and academic achievement.

Nadim et al (2012), found that there is a statistically significant relationship between t researchcreative thinking and academic achievement and the strongest relationship was found between fluidity and academic achievement..

Hassanzadeh and Imani Far (2010) in an investigation on the relationship between creativity and self-esteem with academic achievement found that there is no significant relationship between creativity and academic achievement.

Zahabioun and Ahmadi (2009) found that the relationship between the amount of using creative thinking and gender variable, parents' educational level is not significantly related to academic achievement..

Dahl (2012) in an experiment that was conducted on secondary school students showed that in case of the elimination of the effect of intelligence, there is no significant relationship between creativity and academic achievement.

The results obtained in this study showed different results with the findings of Hassanzadeh and Imanifar(2010), Zahabioun and Ahmadi (2009) and Dahl (2012), respectively. However,the results are consistant with the results of Asha (1980), Estrocher et al (1996), Eye (1999), Nelson and Cox (2004), Ronko (2007), Peterson et al (2008), and Niaz and Soud (2008), Zigozia (2010), Naderi et al (2010), Nadim et al(2012) and Jabiben and Ahmadkhan (2013) .

Third research hypothesis: "There is a significant relationship between female and male students regarding the emotional intelligence."

Since $(42 / 0 p=$ and $63 / 0=F, 06 / 0 p=$ and $42 / 3=F, 59 / 0 p=$ and $28 / 0=F, 11 / 0 p=$ and $53 / 2=F)$ then, there is no significant relationship between male and female students in terms of self-awareness, self-management, social awareness and relationship management.

Samari and Tahmasbi (2007) examining the relationship between emotional intelligence and academic achievement, age and sex of the students found that, although there is a significant difference between males and females in the subscales of emotional intelligence, but there was no significant difference in the total score of emotional intelligence

Zare research [5] on the effect of gender on emotional intelligence scores showed that the total score of emotional intelligence was not significantly different between females and males.

Rahnama and Abdolmaleki (2009) in their study found that there was no significant relationship between males and females in the two variables of emotional intelligence and creative thinking..

Results of Chan (2005) study showed that creativity and emotional intelligence scores did not change with age and gender [29].

In Rahim zadeh (2001) study, there was no significant difference in total emotional intelligence score between males and females. Comparing the components of emotional intelligence (self-awareness, self-control and social skills), 
only the element of social consciousness in females was more than boys, but there was no significant difference in the other components. Mimroot (2011) in a study found that gender has no significant effect on emotional intelligence.

Based on the findings of Mansouri (2001), there is a statistically significant relationship between the total scores of test, component of self-awareness, self-control and social consciousness.

However, there were no significant relationship between males and females in components of the self-inspiration and social skills [21]

Research conducted by Hanifiand Jouibari (2008), showed that there are differences between male and female students' emotional intelligence. KhaliliAzar Research (1386), showed thatemotional intelligence in girls is higher than boys. HasanZadeh and SadatiKiadehi (2008) research showed that emotional intelligence is different in female and male managers.

Finally, it could be concluded that the present study is consistant with researches by Rajimzadeh (2001), Samari and Tahmasbi (2007), Rahnama and Abdolmaleki (2009), Chan (2005) and Mimroot (2011). But the results are not in line with studies by Mansour (2001), Khalil Azar (2007), Hanifi and Jouybari (2008), and HasanZadeh and SadatiKiadehi (2009).Based on the consistency of the obtained results with most of the other researches the discrepencies with other studies can be related with personal differences and educational factors.Manyresearchers believe that individual and educational factors and cognitive and social nature have the highest impact in this regard.On the other hand, the educational facilities available to students, and parents' educational level are important in the development of emotional intelligence

Fourth research hypothesis: "There is a significant difference between female and male students in terms of creative thinking".

Since $(14 / 0 p=$ and $18 / 2=F, 38 / 0 p=$ and $75 / 0=F, 98 / 0 p=$ and $0001 / 0=F, 96 / 0 p=$ and $002 / 0=F)$ then there is no significant difference between male and female students regarding fluidity,creativity,flexibility and expansion.

Sedighi (2011) results suggested that males had significantly no difference with females in all variables of verbal creativity except creativity scale.

Zahabioun and Ahmadi (2009) found that there is no significant relationship between the use of creative thinking and sex variable, parents' education level and academic achievement.

Jafari (1994), HadiNejad (2008), Haji Jafari (2006) and Naderpour (1998) in their study concluded that there was no statistically significant difference between creativity and gender [11].

Karimi (2000) showed that there is a significant difference between the two sexes in terms of creativity. In his study males were significantly superior in creativity compared to females.

The results of this study indicate consistency with studies by Sedighi (2011), Jafari (1994), Naderpour (1998), Haj Jafari (2006), HadiNejad (2008) and Zahabioun and Ahmadi (2009), respectively. But it was not in line with Karimi (2000) study. This difference might be due to different performance of this plan in public schools since educational facilities in public schools copared to private and semipublic schools are rather little and this lack of facility affects the improvement of creative thinking in students.

\section{Conclusion}

Different results can be observed in literature regarding the inconsistency in the relationship between emotional intelligence and academic achievement. This is probably due to the lack of attention to the theoretical framework and the tests used in previous studies. Probably one of the reasons for the lack of correlation in this study is students' misconception of emotions in answering the questions. In this regard, we can cite Bradberry and Greaves that said: only 26 percent of the population that we studied were able to identify their emotions correctly as they happened [3].

Results of Sharifi et al (2011) study shows that there is no significant relationship between creativity and emotional intelligence with academic achievement.It could be concluded from the mentioned study that teaching-learning process at elementary schools is more based on verbal relationships and is less focused on higher mental levels such as combination,criticalthinking,problem solving and emotional intelligence.

Probably one of the reasons of difference in the obtained result of answering the creativity test is the lack of applicability of creativity measuring tests. This is because these tests consider creativity as a single thing while creativity happens at a certain cognitive domain. These tests view creativity as a general phenomenon not a professional term. Therefore their applicable value is rather limited [4].

In Poursaedstudy,there is a significant relationship between fluidity,novelty,flexibility and expansion that are 76.0,75.0,68.0,56.0 respectively. According to the mentioned calculations, the importance of each dimension is accordingly as follows:1:fluidity and novelty 2:flexibility 3:expansion. Therefore,fluidity and novelty have more role in 
creativity .In the present study results were relatively the same. Therefore it seems relevant to put more emphasis on fluidity and novelycomponents' while preparing creativity boosting programs.

The effective factor in developing creative thinking include experiences and prior information of students.If students information and structure is fulfilling, there is more probability of creative thinking occurrence. However,it seems that despite of having many facilities, students have little information since their time is wasted on violent computer games rather than games that boosts their creativity.

On the other hand, teachers choose simple methods for teaching instead of setting new questions and using various facilities. They choose methods such as lecturing instead of cooperating methos.In this study, public schools were investigated which unfortunately are less supervised compared to private schools.

Another factor for low creative thinking scores in this study is due to the low literacy of parents and consequently improper parents' behavior with their children. According to Jahani (2008) parents who wish to develop creative thinking in their children criticize them less,do not reprimand their dreaming and do not frighten or punish them unreasonably. Infact,thiscan not be expected from parents with low literacy.Another reason for low creative thinking score might be due to low emotional intelligence score.

Banihashemian (2012) purports: Many people believe that creativity is the a subset of emotional intelligence which means it is in fact one if the componants of emotional intelligence. Emotional intelligence enable the person to increase or maintain positive mood, thus he will indirectly increases the creative thinking.

What can be deduced from the literature and studies in the field of creative thinking is that creative is teachable and could be taught to children and teenagers by methods and effective content.

However, there is little agreement among experts on the content and the ways in which creativity can be cultivated.Guildford suggests thinking training, Dobono believes in fostering thinking style through courses and Lipman believes that through educating concepts and philosophical connotations creative thinking can be improved[15].

- Suggestions

- Greater emphasis of education system on improving social skills, emotional intelligence and its different aspects in elementary school

- Designing learning spaces in a way that leads to fostering emotional intelligence and creative thinking

- Emotional literacy, which in turn led to the development of emotional intelligence should be considered as one of the most important issues in teacher education

- Emotional intelligence raising classes for parents to know what their children are taught in school and what they should teach to their children

\section{References}

AdemolaOlatoye, Akintunde,S.O., \& Yakasi,M.I. (2010). Emotional intelligence, creativity and academic achievement of business administration students. Electronic Journal of Research in Educational Psychology,8(2)763-786.

Amir Hosseini, Khosro (2009). Creativity \& Innovation (Basics, principles and techniques). Tehran: Aref publication. Volume 3.

Bradberry,Travis\& Greaves, Jean. (2011). Emotional intelligence, Qazvin literary publications.[In Persian].

BaniHashemian, K., Fakhri, M. K., and Mirzaian, B. (2012). General health between emotional intelligence and creativity among students of Islamic Azad University, Sari Medical School. Qom University of Medical Sciences.Vol, 6. No, 2.Pp, 57-53.

Dehshiri, Gh. (2003). The relationship between emotional intelligence and academic achievement. News and research and consulting. Volume 5. No. 18, 105-97[In Persian].

Dhall. S. (2012). A Study of creativity in relation to reactions of frustration and academic achievement of secondary school. Indian. J. Innovations, Vol.1,No.6

Farmahini, M., Malik, J., and Rashid, Z (2008). Relationship between emotional intelligence, self-regulation learning and classroom goal structure in students' academic achievement in first grade secondary Qorveh city. Scientific Journal of Daneshvar, Shahed University. Vol, 15, No. 30[In Persian].

GolestanJahromi, F., M. Shahriari, May, S., and A. Mahmoud Farid, AA. (2009). the relationship between emotional intelligence and academic achievement of gifted and regular students. Journal of Educational Psychology, University of Sistan and Baluchestan. No. 19, 79-98[In Persian].

Haghani, F., Aminian, B., Tahereh,C. (2011). Do teachers who are great from their students' perspective have higher emotional intelligence? Iranian Journal of Medical Education Development Center.8 (2), 132-140.

Hashemi, S. (2009). Relationship between emotional intelligence, creativity, excitement and creativity of students in the Arts, Letters and Sciences. NEW THOUGHTS ON EDUCATION. University, School of Education and Psychology, Volume 5, No. 2,79 -102[In Persian].

Hassanzadeh, Ramezan., and Imani Far, Parisa. (2010). The relationship between creativity and self-esteem and academic achievement in adolescents and young adults. Journal of Sociology. First year. Prior to the third issue, 65-55[In Persian]. 
Hassanzadeh, R., and Sadat Kyadhy, SM. (2009). Assessment of emotional intelligence and their relationship with their demographic characteristics. Educational Research. Islamic Azad University Bojnord. Vol,5. No,20[In Persian].

Hanifi, F., and streams, Azita. (2010). Relationship between emotional intelligence and academic achievement of high school students in Tehran. Journal - Research in Educational Administration. No, 44 -29[In Persian].

Hemmati, A. (2008). Personal barriers to creativity from the perspective of a comparative study of male and female teachers in Urmia region 2[In Persian].

Jabeen, S. \& Ahmed Khan,M. (2013). A study of creative thinking abilities and self concept of high and low achievers. Unique Journal of Educational Research.Vol.1(1),pp 001-011

Jahani, Jaafar. (2008). Teaching creative thinking in adolescents: research-oriented approach. NEW THOUGHTS ON EDUCATION. School of Education and Psychology, University of Al-Zahra (sa). Fourth period, 54-29[In Persian].

JiewnSong, L., Hung, G., Peng, K., Law, K. S. (2009). The differential effect of general mental ability \& emotional intelligence on academic performance and social interaction.

Karimi, A. (2000). Investigate the relationship between creativity with anxiety, gender, educational attainment and social status of a group of third grade students. MS Thesis, University of Shiraz[In Persian].

KeshavarziArshadi, p. (2009). Effect of identity style and emotional intelligence predict achievement and academic performance of graduate students. Thought and behavior. The fourth period. No. 13, 43-56[In Persian].

KhaliliAzar H.. (2007). Comparison of emotional intelligence bright and normal students and its relationship to academic achievement. Knowledge and Research in Education. Azad University Branch. No, 14.[In Persian].

Lalifaz, A., and Askari, A. (2009). Emotional intelligence and demographic variables in predicting academic achievement of gifted students. Studies of Education and Psychology, (1) 9: 167-81[In Persian].

Lyvarjany, flames, and Ghaffar, Sarah. (2010). Relationship between emotional intelligence and social skills and academic achievement of high school students in the city of Tabriz in 1389-1388 academic year. Education. Third year. No. 9, 71-88[In Persian].

Mansouri, A. (2001). Relationship between emotional intelligence and academic achievement. MA thesis. AllamehTabatabai University [In Persian].

Moghanyan, M. (2011). The relationship between emotional intelligence and improve the effectiveness of management in the Department of Mechanical authorities' opinion. MA thesis. Azad University, Central Tehran Branch[In Persian].

Mimrot, Bharat, H. (2011). Role of area of residence, sex in developing emotional intelligence and self of adolescents. International Referred Research Journals. June Vol. 2,issue 21

Nadeem. M., Aness. M., Khizar.A.,Naseer. M, Muhammad.G. (2012). Relationship of creative thinking with the academic achievement of secondary school students. International Interdisciplinary Journal of Education,Vol.1,Issue 3

Naderi. H., Rohani. A., Tengku. A., Jamluddin. S \&Kumar,V. (2010). Relationship between creativity and academic achievement, A Study of Gender Differences. Journal of American Science, 6(1):181-190

Niaz, Mansoor.,\& Saud, Grecia. (2008). Academic performance of high school students and a function of mental capacity, cognitive style, mobility - fixity dimension, and creativity. Journal of Creative Behavior. VOL. 34, Number1

NorouziKouhdasht, R.; Mahdian, M. J; AfzaliNaeini, M. (2013). The relationship between emotional intelligence and three thinking style in male and female students in Tehran. International Journal of Learning Development. Vol.3.No3.110-119

Nofersty, Azam, Moein o Ighorabayi, Fatima (2010). Emotional intelligence and creativity at the State University of Tehran. Developmental Psychology: Psychology of Persia. Seventh year. No. 26, 185-175[In Persian].

NoferestyAzam. (2012). Seminar on emotional intelligence and creativity. Asr-e Iran news website [In Persian].

Pour Saeed, Syed Masood. (2001). Examine the relationship between creativity and scientific advancement of new members of the faculty. No, 26. [In Persian].

Rahnema, A. and Maleki, Jamal (2009). Relationship between emotional intelligence and academic achievement in students' creativity and control. NEW THOUGHTS ON EDUCATION. School of Education and Psychology. Volume 5, Issue 2.78 - 55[In Persian].

Ramezani, A. (2009). Study of the attitudes of student creativity in schools, schools for boys and girls Parenting Talented Urmia. MA thesis, University of Urmia [In Persian].

Samari, Ali Akbar; Tahmasby, Fahimeh (2007). Relationship between emotional intelligence and academic achievement in students. Journal of Mental Health. No. 35, 36, 128-121[In Persian].

Sharifi, N.; Ganji, H.; Hashemian, Kianoush and does Najafi, J (2012). School of Life, institutional cognitive abilities, creativity and emotional intelligence of students. Journal of Education. No. 111, 93-75[In Persian].

Sharifi, N.; Ganji, H.; Hashemian, Kianoush and does Najafi, J (2012). Comparing the contribution of cognitive intelligence, creativity and emotional intelligence in predicting academic achievement of students in different academic levels. New Journal of Psychology, Industrial / Organizational. Vol,2. No. 6, 29-17[In Persian].

Siddiqi. S. (2011). A comparative study of creativity among boys and girls of class VII. Educational Review.Vol,49.No,2

Singh, S \&Tukral, P. (2009). The Role of anxiety in achievement . Journal of Exercise Science and Physiotherapy.Vol.5,No.2:122-125

Sobhani, R. (2004). The study of emotional intelligence and academic achievement hardiness. MA thesis. Islamic Azad University, Science and Research.[In Persian].

Soroudi, R \&Rahimi, N. (2010). Comparison of emotional intelligence in urban and rural primary school girls in Qeshm city. Islamic Azad University of Qeshm [In Persian].

Sousa, S \& Amor, D. J. (2010). Impact of family vs school factors on cross-national disparties in academic achievement . Social Science Research Network (SSRN). 
Sternberg, R. J., Forsythe, G. B., \& Williams, S. (2002). Practical intelligence. Newyork.Cambridge University Press.

Tamnayi Far, Mohammad Reza; SedighiArfaeiFariborz, \& Salami Mohammad Abadi, Fatemeh (2010). Relationship between emotional intelligence, self-esteem, and academic achievement. Journal of Instructional Strategies. 3 (3), 121-126 [In Persian].

Vernon,P.A.. Petrides, K.V., Bratko. D., \&Schermer, J. A. (2008). A

behavioral genetic study of trait emotional intelligence .Vol 8,635-642

Woitaszewski, S.A \&Aalsama, M.C (2004). The contribution of emotional intelligence to social and academic success of gifted adolescence as measured by the multifactor emotional intelligence scale. Roper Review. Vol.27. pp 30-45.

Yousefi, F, Mokhayar Mohammad (2003). Examine the relationship between formal reasoning, emotional awareness and academic achievement in a group of gifted and regular students in Shiraz. Journal of Psychology and Educational Sciences, 32 (2) 175200[In Persian].

Zahabion, L. and Ahmadi, Gholam Reza. (2009). Creative thinking and its relationship to academic achievement in university students Journal. Knowledge and Research in Education - Curriculum. No. 21, 78-61[In Persian].

Zare, A.. (2001). Comparing the contribution of emotional intelligence and general intelligence in predicting academic achievement of junior secondary school students in Shiraz. MA thesis. Iran University of Medical Sciences [In Persian]. 